\title{
A study on the impact of cement type and heat stimulation on performance of superplasticizers
}

\section{Zabihollah Tahery $^{1 *}$, Shigeyuki Date ${ }^{2}$}

\author{
1,2 Tokai University, Hiratsuka, Japan
}

\author{
Index Terms \\ Heat Stimulation \\ Superplasticizer \\ Fluidity \\ Flow Loss \\ Cement Mortar
}

Received: 24 December 2016

Accepted: 2 January 2017

Published: 30 June 2017

\begin{abstract}
The objective of this study was to investigate the interaction of different types of cement and superplasticizer admixtures in which the Superplasticizers were stimulated by heating before addition to the mortar. To evaluate the desired impacts, tests on the fluidity and flow loss of mortar were conducted. For better considering the behavior of admixtures under heat stimulation with different types of cement, three types of cement and two types of superplasticizer are used, Polycarboxylic acid-based and Polycarboxylic acid-based ether. The admixtures were heated to $40^{\circ} \mathrm{C}, 50^{\circ} \mathrm{C}$, and $60^{\circ} \mathrm{C}$ for 0.5 hours and 24 hours. Generally, Polycarboxylic acid-based admixtures showed higher flow improvement in $60^{\circ} \mathrm{C}$ heating with all cement types, especially with High Early Cement, in comparison with Polycarboxylic acid-based ether type. The flow loss of mortar was reduced by heat stimulation of admixtures, Polycarboxylic acid-based ether (the product suitable for Ready Mix Concrete) showed significant flow improvement after 15 minutes and kept it to one hour. As the result of this research, it is possible to reduce the admixture dosage and maintain the desired fluidity of mortar or increase the mortar fluidity by applying the heat stimulation technique.
\end{abstract}

(C) 2017 The Author(s). Published by TAF Publishing.

\section{INTRODUCTION}

Superplasticizers (hereinafter SPs) are inseparable part of modern cementitious building materials, such as high performance concrete, self-compacting concrete, etc. However, still incompatibility between binder and Superplasticizer is a big concern. Polycarboxylic acid-based (PC) and Polycarboxylic acid-based ether (PCE) admixtures are non-ionic surface active compounds. The side chains of polyethylene oxide extending to the surface of cement particles migrate on water and the cement particles are dispersed by the steric hindrance of the side chains [1]. Longer side chains gave more fluidity at the same dosage, and a shorter setting time.

Also result of another research [2] shows that longer side chains lead to lower yield stresses, which is the initial requirement for a better fluidity of concrete or mortar. Adsorption of SP in cement particles is another key factor affecting the performance of the SP, fluidity and flow loss of concrete or mortar. SP is believed to work only after the adsorption on cement particles, therefore it is useful to compare their adsorption. The SP with longer side chain had the most dispersing power, although its adsorption ratio is relatively low [3], therefore there is a higher amount of SP to affect the mortar fluidity. The chemical and physical properties of cement, govern the SP adsorption behavior on cement particles. In terms of chemical properties of cement, slump loss will increase with increasing C3A content of cement $[4,5]$.

Physical properties of cement like specific surface area, have an effect on SP adsorption on cement particles. A higher specific surface area of cement particles is expected to increase the SP adsorption and consequently SP demand. In order of chemical properties of cement, with the increasing aluminate content of the cement, the amount of polymer adsorbed is increasing. This result is same as reported by [6] who inspected the adsorption behavior of superplas-

\footnotetext{
*Corresponding author: Zabihollah Tahery

†Email: zabih1168@yahoo.com
} 
ticizers of pure clinker phases. Superplasticizers are produced in a diversity of brands and products, and divided by different classifications on the basis of type and end-use industry. SP affects through mechanisms of electrostatic repulsion and steric hindrance [7]. Efficiencies of PC and PCE type SPs are connected to their chemical structures and particularly with the type, length and arrangement of the backbone and side chains as well as with the presence of functional groups $[8,9,10]$. The efficiency will increase with the number and length of the side chains $[11,12]$.

The side chains of the polymer molecule adsorbed on the cement particles can block them against other cement particles so disabling flocculation leading to the fluidity of cement pastes $[13,14]$. In this research, it is believed that, heat stimulation technique will increase the side chain length of grafted polymers during the heating period by opening the coil-shaped side chains, which causes an improvement of fluidity and decrease of flow loss in fresh cement mortar. This research was intended to study the influence of different cements and SP types, and heat stimulation effect of SP on fluidity and flow loss of fresh cement mortar.

The flow loss of mortar was studied with three cement types which are Ordinary Portland Cement (OPC), High Early Strength Cement $(\mathrm{H})$ and Blast Furnace Slag cement (B), and two products of PCE type, SP2 and SP4, which are classified in order of end-use industry into precast concrete (hereinafter PCa) and ready-mix concrete (hereinafter RMC) products respectively. The heat stimulation technique can be used to increase the flow of mortar or concrete with the same dosing rate of SP, or decrease the dosage of SP and obtain same fluidity of mortar or concrete. The other importance of research is the possibility of more reduction in water-cement ratio, while the admixture dosage and fluidity kept in initially designed level, which insures the durability and quality of the mortar or concrete. Also the result of this research is useful for RMC industries to take in consideration the effect of ambient temperature on performance of the SP, and its effect on the properties of concrete.

\section{LITERATURE REVIEW}

Preparatory phases of a new research are dependent on information from similar studies in the past. According to the existing data about the effects of temperature on the performance of the Superplasticizer admixtures, the researchers studied effect of temperature on the performance of Superplasticizers after the mixing of Superplasticizers

ISSN: 2414-3103

DOI: $10.20474 /$ japs-3.2.4 with mortar, they only applied heat treatment on the mortar containing Superplasticizer. Because of the innovative approach of this research, there were no data about the effects of pre-heat treatment on the structure of Superplasticizer and consequent effects on properties of mortar and concrete.

The performance of SPs is influenced by different factors such as type and dosage of SP, cement type, temperature and mixing procedure, as well as the addition time of the SP to the rest of material $[15,16,17]$. Delaying addition of the SP to the concrete mix, will cause the quick absorption of water molecules by reactive cementitious particles, and the hydrated cover on these elements is formed beforehand: the C3S and C2S can adsorb sufficient SP molecules for their dispersion. In addition, it was stated that a little delayed addition would produce a more workable concrete or cement paste than an immediate addition [18]. It was reported by other researchers that, competencies of the PC and PCE, SPs have direct relation to the chemical structures of those products, and predominantly with the type, length and arrangement of the backbone and side chains as well as with the existence of some functional groups [3]. It means that sometimes the SP products of the same bases behave differently because of the small changes in their chemical structure or functional groups in their chemical structure.

The ambient temperature is also known to have effect on the performance of the superplasticizer admixtures. Recently some limited researches have been done in this field. Rheological experiments were carried out on three different types of superplasticizer, a sulfonated naphthalene formaldehyde condensate, a sulfonated acetone formaldehyde condensate and a carboxylated polymer, at temperatures from $25^{\circ} \mathrm{C}$ to $120^{\circ} \mathrm{C}$ at a high temperature, high pressure rotational viscometer [19]. At temperatures of $100^{\circ} \mathrm{C}$ and $120^{\circ} \mathrm{C}$, plastic viscosity and yield point values were notably lower than at temperatures of $20^{\circ} \mathrm{C}$ to $80^{\circ} \mathrm{C}$. The researchers applied the heat treatment to the mortar containing SPs.

\section{METHODOLOGY}

The mixing process was, according to the JIS R 5201 "Physical testing methods for cement". For making mortar with heat stimulated admixture, at first fine aggregate and cement was mixed for 30 seconds. Then heat stimulated admixture was added to the mixing water after taking out form thermostatic chamber and mixed for 60 seconds with premix of cement and fine aggregate. Finally the mortar was 
mixed again for 30 seconds at higher speed of the mixer. The same procedure was used to prepare the mortar with non-heated admixture. The ambient temperature of mixing was $20 \pm 2{ }^{\circ} \mathrm{C}$. To confirm the changes in fluidity and flow loss of mortar after heat stimulation of admixture, the flow table of JIS R 5201"Physical testing methods for cement" was used. The flow improvement $(\Delta$ Flow) of mortar was measured in 0 Struck and 15 Struck of flow table.

$\Delta \operatorname{Flow}(\%)=\frac{\left(F_{1}-F_{f}\right)}{F_{1}} \times 100$

In Eq. (1) $F_{I}$ is the flow of mortar with non-heated SP and FF is the flow of mortar containing heat stimulated SPs. For measurement of flow loss, the mortar spread was the average of two perpendicularly crossing diameters. From the spread $(\mathrm{F})$, relative flow area $(\tilde{\mathrm{A}})$ was calculated by Eq. (2) [1].

$(\tilde{A})=\left(\frac{F}{r 0}\right)^{2}-1$

Where $\mathrm{r} 0=50 \mathrm{~mm}$, bottom cone radius. The average standard deviation using the above mentioned method determining flow area is 1.12 . The objective of this research is to investigate the influence of cement and SP type, and heat stimulation effect of SP on: fresh properties of cement mortar prepared by three types of cement and two types of SP. In order to achieve this goal, several objectives are set out:

1- Peak heating temperature and time for each SP, and impact of heating temperature rise on performance of SP.

2- Effect of cement type on SP demand and performance of heat stimulated SP.

3- Effect of SP type on performance of heat stimulated SP.

4- Influence of cement type and SP type on flow loss of mortar containing heat stimulated SP.

\section{A. Materials Used}

The materials used in this research are shown in Table 2. The mortar's water-cement ratio was $30 \%$ and sand-cement ratio was 2.0. The admixtures' dosing rates are shown in Table 3. These dosages were used to obtain a target flow of approximately $120 \mathrm{~mm}$ at ( 0 stroke of flow table) and $200 \mathrm{~mm}$ at (15 strokes of flow table), before heating the admixtures. Table 4 shows cement physical and chemical compositions.

\section{B. Admixture Heating Conditions}

The heating conditions of admixture are shown in Table 1. A thermostatic chamber was used to control the heating temperature. The admixtures were heated at three temperatures $40^{\circ} \mathrm{C}, 50^{\circ} \mathrm{C}$ and $60^{\circ} \mathrm{C}$. The tolerance of heating was $\pm 1{ }^{0} \mathrm{C}$. The admixtures were kept under heating for 0.5 hours and 24 hours.

TABLE 1

ADMIXTURE HEATING CONDITIONS

\begin{tabular}{ccc}
\hline \hline Heating conditions & Admixture Heating Temp ${ }^{0} \mathrm{C}$ & Admixture Heating Time $(\mathrm{H})$ \\
\hline Case 1 & 40,50 & 0.5 \\
Case 2 & 60 & 0.5 \\
Case 3 & 60 & 24 \\
\hline \hline
\end{tabular}

\section{RESULTS}

\section{A. Peak Heating Temperature and Time of SP and Impact of Heating Temperature Rise on Performance of the SP}

Impact of temperature rise on performance of the SP and consequently on fluidity of mortar is shown in Figs. 1,2 , and 3 with $\mathrm{OPC}, \mathrm{H}$ and $\mathrm{B}$ cement types respectively. The SP was heated for 0.5 hours to $40^{\circ} \mathrm{C}, 50^{\circ} \mathrm{C}$ and $60^{\circ} \mathrm{C}$. The SP3 showed the best performance, in order of mortar flow improvement at $50^{\circ} \mathrm{C}$ heating temperature with all cement types. It seems that the optimum heating temperature was $50^{\circ} \mathrm{C}$ for SP3. The other three remaining admixtures SP1, SP2, and SP4 had shown mortar flow improvement with increasing the heating temperature with all cement types. The optimum heating temperature for SP1, SP2, and SP4 was $60^{\circ} \mathrm{C}$. Generally PC type SP showed better flow improvement with temperature rise than PCE type SP. For better understanding the effect of heat stimulation time on the performance of the SP, SP1 and SP2 were heated at $60^{\circ} \mathrm{C}$ temperature for 24 hours. The flow improvement results from 24 hours' heating time of SP1 and SP2 were compared with their 0.5-hour heating time, a flow improvement of more than $8 \%$ was observed with SP1, the SP2 has shown more than $12 \%$ flow improvement in (0 stroke). In (15 strokes), SP1 and SP2 have shown about $6 \%$ and $9 \%$ flow improvements respectively. In case of 24 hours' heating time at $60^{\circ} \mathrm{C}$ temperature for SP3 and SP4, SP3 showed about 1-2 \% flow improvement (0 strokes) in comparison with a 0.5 -hour heating time, and SP4 has shown more than $40 \%$ flow improvement. In a study of (15 strokes) flow 
measurement, SP3 showed a better flow improvement than SP4 in comparison with a 0.5-hour heating time. It can be observed that all admixtures showed increase in flow with 24 hours' heating time.

TABLE 2

MATERIAL USED

\begin{tabular}{ccc}
\hline \hline Material & Symbol & Description \\
\hline \multirow{4}{*}{ Cement } & OPC & Ordinary Portland cement \\
& H & High early cement \\
Fine Aggregate & B & Blast furnace slag cement \\
& SP1 & River sand from Kanagawa, density*: $2.685 \mathrm{~g} / \mathrm{cm} 3$ \\
Super- plasticizer & PP2 & Type of AE: (Polycarboxylic acid-based \\
& SP3 & Polycarboxylic acid-based ether) Precast Concrete \\
& SP4 & Type of AE: (Polycarboxylic acid-based ether) Ready Mic Concrete \\
\hline *: In saturated
\end{tabular}

TABLE 3

ADMIXTURE DOSAGE

\begin{tabular}{ccc}
\hline \hline Cement & Admixture & Ad/C $(\%)^{*}$ \\
\hline \multirow{4}{*}{ OPC } & SP1 & 0.56 \\
& SP2 & 0.8 \\
& SP3 & 1 \\
& SP4 & 1.15 \\
& SP1 & 0.58 \\
H & SP2 & 0.92 \\
& SP3 & 1.68 \\
& SP4 & 1.18 \\
& SP1 & 0.4 \\
& SP2 & 0.42 \\
B & SP3 & 0.5 \\
& SP4 & 0.7 \\
\hline *: liquid dosages & &
\end{tabular}

TABLE 4

CEMENT PHYSICAL AND CHEMICAL COMPOSITIONS

\begin{tabular}{cccc}
\hline \hline Cement type & & & \\
\hline Item & OPC & H & B \\
\hline MgO \% & 1.41 & 1.44 & 3.31 \\
So3 \% & 2.1 & 2.88 & 2.05 \\
CL- \% & 0.015 & 0.005 & 0.010 \\
Na2Oeq & 0.5 & 0.47 & - \\
C3S \% & 56 & 63 & - \\
C2S \% & 18 & 12 & - \\
C3A \% & 9 & 9 & - \\
C4AF \% & 9 & 8 & - \\
Density g/cm3 & 3.16 & 3.14 & 3.04 \\
Spec. Surf. area cm2/g & 3344 & 4490 & 3750 \\
\hline \hline$-=$ not given by supplier & & &
\end{tabular}

\section{B. Effect of Cement Type on SP Demand and Performance of Heat Stimulated SP}

SP is believed to work only after the adsorption on cement particles, thus it is useful to compare their adsorption. Such as shown in Table 3, the highest SP demand was observed with $\mathrm{H}$ cement and followed by OPC and B cement. The $\mathrm{H}$ cement and OPC contain higher amounts of aluminate content in comparison with B cement. The report by other researchers has shown that, with the increasing aluminate content of the cement, the amount of polymer adsorbed is increased [2].

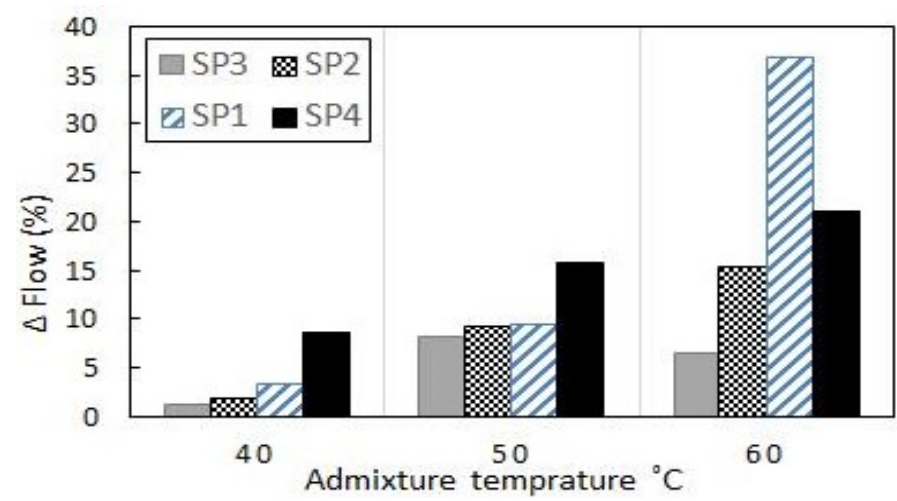

Fig. 1. Impact of heating temperature on performance of SP with OPC

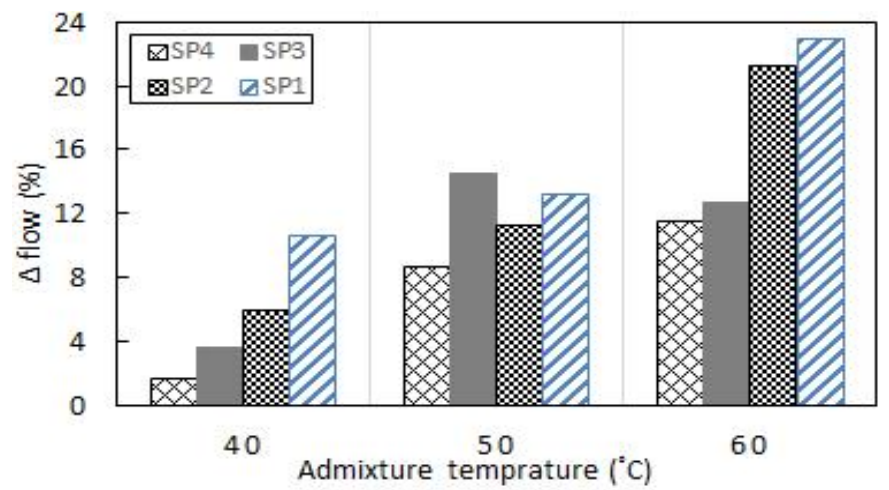

Fig. 2. Effect of heating temperature on performance of SP with H Cement

This result is same as reported by Yoshioka et al.6, their research result determines that SPs adsorb on $\mathrm{C} 3 \mathrm{~A}$ and $\mathrm{C} 4 \mathrm{AF}$ and their hydration products rather than calcium silicate phases. At a low water-cement ratio, the surface of interstitial phases, especially of C3A and C4AF is covered by the adsorbed SP, thus very little SP is in the pore 
solution [1]. So a higher amount of SP is needed to achieve desirable flow in concrete or mortar.

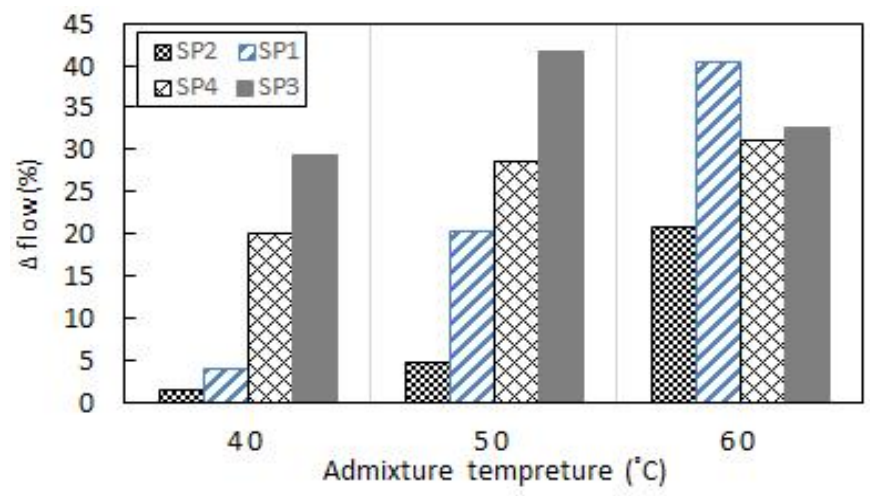

Fig. 3. Influence of heating temperature on performance of SP with B Cement

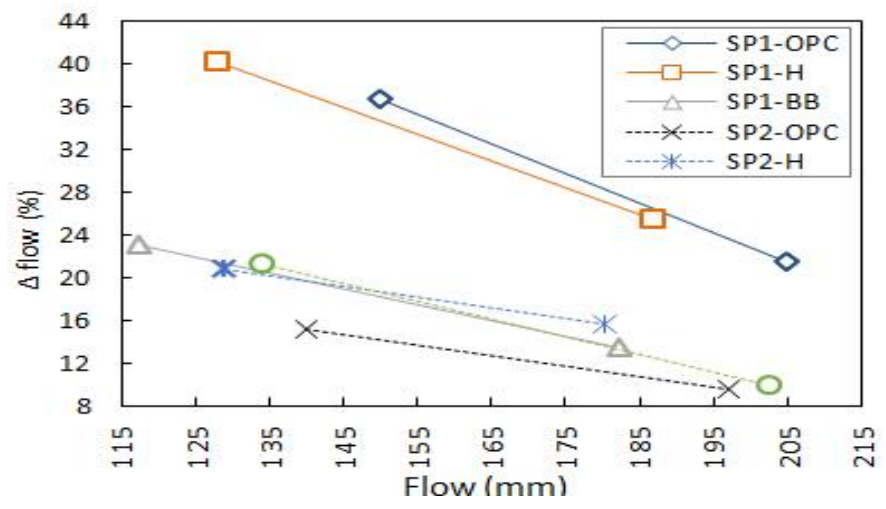

Fig. 4. Effect of cement types on flow improvement of SP1 and SP2

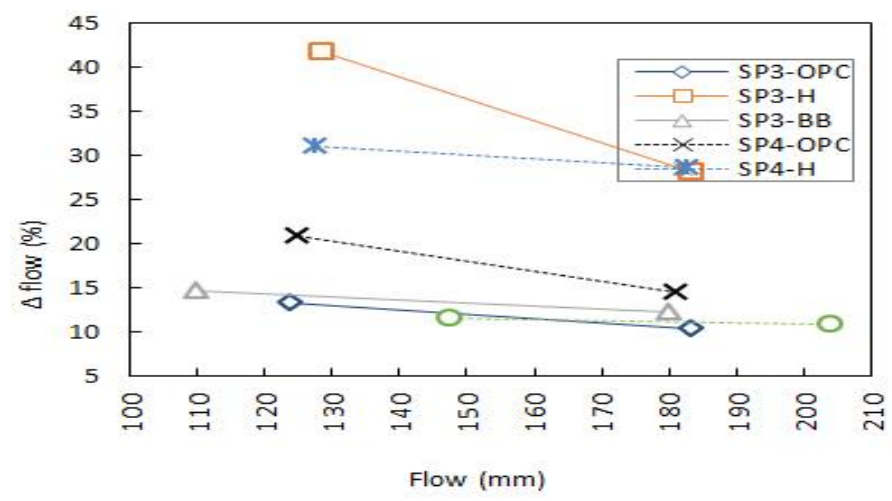

Fig. 5. Effect of cement types on flow improvement of SP3 and SP4

Consequently, it will increase the SP demand in cements with higher $\mathrm{C} 3 \mathrm{~A}$ and $\mathrm{C} 4 \mathrm{AF}$ content. The lower dosages of SP have shown a suitable performance with B cement in both heat stimulated and non-heated conditions, it is generally believed that Cement-SP interaction is mainly due to the effect of C3A, gypsum (sulfate) and alkali content [20, 21]. Other researchers reported that the performance of testing admixtures is clearly better with low C3A, and C3S and alkali content cement $[22,23]$.

Another factor which affects the SP demand, is the Blaine fineness of the cement. As shown in Table 4, the Blain fineness of the $\mathrm{H}$ cement is $4490 \mathrm{~g} / \mathrm{cm} 2$ that is higher than Blain fineness of OPC and B cement. Because most of the surface area comes from the smallest particles, so the SP in $\mathrm{H}$ cement must cover more areas in comparison with OPC and B cement, therefore more amounts of SP are needed. In terms of cement type, performances of SPs in order of changes in fluidity of fresh mortars are shown in Fig. 4 and Fig. 5, the SP was heated for 0.5 hours to $40^{\circ} \mathrm{C}$, $50^{\circ} \mathrm{C}$ and $60^{\circ} \mathrm{C}$.

From all cement types, the highest flow improvement was observed with $\mathrm{H}$ cement and heat stimulated SP3, in comparison with non-heated condition. As displayed in Fig. 5, Heated SP3 showed highest flow improvement of $43 \%$ in ( 0 stroke) with $\mathrm{H}$ cement. SP1 revealed more than $40 \%$ flow improvement in ( 0 stroke), the results are visible in Fig. 4. After the $\mathrm{H}$ cement, the highest flow improvement was demonstrated by OPC, the OPC with heat stimulated SP1 showed more than 36\% flow improvement in (0 stroke) and more than $20 \%$ in (15 strokes) flow measurement. The B cement showed lowest flow improvement in comparison with OPC and $\mathrm{H}$ cement types, the highest flow improvement with B cement was about $23 \%$ in (0 stroke) and $14 \%$ in (15 strokes) flow measurement with SP1. The high flow improvement in $\mathrm{H}$ cement appears related to its Blain fineness, which is more than that of OPC and B cement, hence it has smaller particles. In constant amount of cement, more particles exist in $\mathrm{H}$ cement, they can be covered widespread and easily by expanded side chains of SP (by heat stimulation) which cause more steric hindrance by SP, and consequently significant fluidity.

\section{Influence of Cement and SP Types on Flow Loss of Mor- tar Containing Heat Stimulated SP}

The fluidity decreases with time after mixing of the mortars. This decrease in the fluidity is named slump loss. It is generally believed that not only SPs of different base groups behave differently, but even SPs of the same base group behave differently with same cement type. Flow loss is related 
to the degree of hydration, which varies with SP type and dosage. The hydration of interstitial phases occurs mainly during the first hour just after mixing with water. Fluidity would then be related more to the $\mathrm{C} 3 \mathrm{~S} / \mathrm{C} 2 \mathrm{~S}$ ratio, a higher ratio would give a higher fluidity [1]. From chemical properties of cements in Table 3, it is obvious that $\mathrm{H}$ cement has a higher $\mathrm{C} 3 \mathrm{~S} / \mathrm{C} 2 \mathrm{~S}$ ratio than OPC, it may be the reason of more fluidity of mortar containing PCa type SP with this cement type.

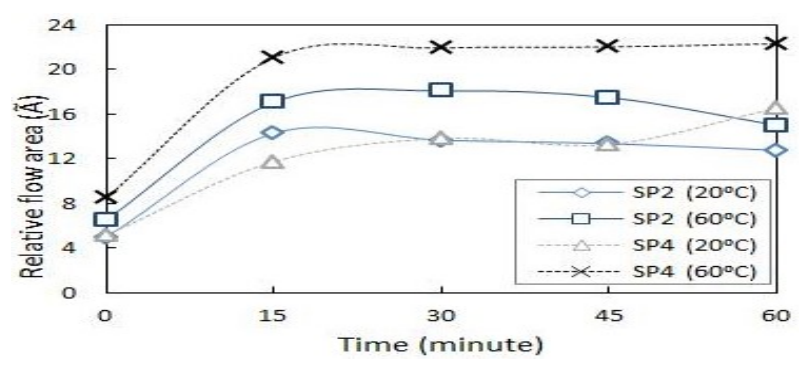

Fig. 6 . Flow loss behavior of mortar containing heated SP with OPC

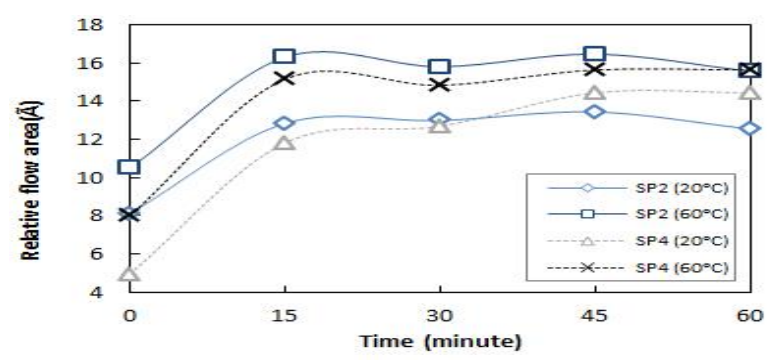

Fig. 7. Flow loss behavior of mortar containing heated SP with $\mathrm{H}$ cement

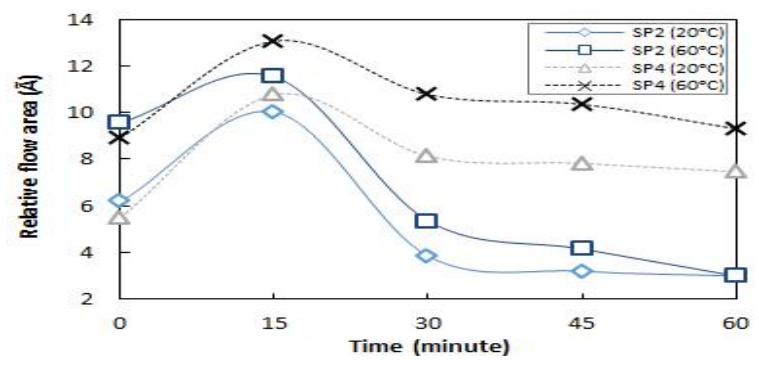

Fig. 8. Flow loss behavior of mortar containing heated SP with B cement

In this research the PCE type SPs were heated at $60^{\circ} \mathrm{C}$ for 0.5 hours. As it is visible in the Figs. 6, 7, and 8, the flow loss behavior of the mortar does not change considerably by heat stimulation of PCE type SPs, but it only shifted into a higher level of fluidity. Only slight changes in flow loss behavior were observed by heat stimulation technique, the flow was more improved in the initial flow measurement approximately until 15 minutes with PCa type, but more slump retention was observed with RMC type until one hour in comparison with non-heated condition. The RMC type SP showed highest fluidity, and flow retention with OPC, it's followed by $\mathrm{H}$ and B cements. After about 15 minutes, the graph of heat stimulated SP2 (PCa type) showed a steep decrease and it converged to the non-heated SP flow until one hour with B cement.

Generally, both PCa and RMC products showed remarkable flow improvement after 15 minutes, either in non-heated or heat stimulated conditions. The SP2, which is a PCa product, does not contain slump retention polymer, it showed remarkable performance in order of mortar flow improvement with all cement types in the initial flow measurements, but it showed low slump retention after one hour with OPC, and B cement. After 15 minutes, the PCa type SP exposed fluidity decreasing with time with all cement types. The graph of the SP4 (RMC) which contains slump retention polymer showed a mild decrease with B cement after 15 minutes, but after 30 minutes, it exposed nearly constant fluidity until one hour. With $\mathrm{H}$ cement and OPC, the graph of SP4 saved approximately constant fluidity with time from 15 minutes to one hour. Flow loss is lower for mortars containing RMC type SPs than mortars containing PCa type. In this study, it is believed that SP structure was expanded by heat stimulation technique and consequently flow of the mortar was improved.

\section{DISCUSSION AND CONCLUSION}

\section{A. Discussion of Results}

The effect of heat stimulation technique on increasing of polymer side chains is demonstrated in Fig. 9 [24]. The third generation of SPs are comb-shaped polycarboxylate-based polymers. They are adsorbed on the cement particles and act as dispersants mainly by steric hindrance [25]. The length of side chains has influence on rheology of cement-polycarboxylate combinations. It is reported that longer side chains gave a lower yield stress, therefore it will cause more fluidity of the mortar. In a previous research [26], rheology was improved with increasing side chain length for polycarboxylate ether type SP with quite short side chains. The hypothesis of this research 
is that heat stimulation of SPs may cause the opening and elongation of coil-shaped side chains of polymer, the longer side chains will provide more steric hindrance by polymer on cement grains and consequently more fluidity of the concrete or cement mortar. The results comply well with the assumption of this study, as stated in section A of the results, increasing of the temperature increased the fluidity of the mortar. It shows the possibility of increase in side chain length of the SP molecules. The H cement which contains higher amounts of aluminate content and has larger specific surface area absorbed more SP and showed more fluidity in comparison with B cement, these results confirm to the results reported by [6].

\section{B. Conclusion}

The effect of cement type and heat stimulated SP, on fluidity and flow loss of fresh cement mortar was examined. From the test results, following conclusions can be drawn:

1. PC type SP showed better flow improvement with temperature rise than PCE type SP.

2. The results from 24 hours' heating time of SP showed remarkable flow improvement compared with their 0.5 -hour heating time.

3. The highest SP demand was observed with $\mathrm{H}$ cement and followed by OPC. The B cement showed lowest SP demand. 4. From all cement types, the highest flow improvement was observed with $\mathrm{H}$ cement and heat stimulated SP, Followed by OPC, the B cement showed lowest flow improvement.

5. Generally PC type SP exposed better flow improvement by heat stimulation technique, than PCE type.

6 . The flow loss behavior of the mortar did not change considerably by heat stimulation of PCE type SPs, but it only shifted into a higher level of fluidity.

7. The RMC type heat stimulated SP revealed better flow retention with $\mathrm{OPC}$, it's followed by $\mathrm{H}$ and $\mathrm{B}$ cements.

In addition, the results of this study are useful for ready-mix concrete plants that stock the admixture in storage tanks outside and under the direct sunlight. In extremely hot days in summer season, there is strong possibility of increasing the temperature of the admixture storage tank, therefore unexpected changes in fresh and mechanical properties of the mortar or concrete may occur. Furthermore the design and production of a more workable concrete at constant dosage of the SP can be realized with heat stimulation technique.

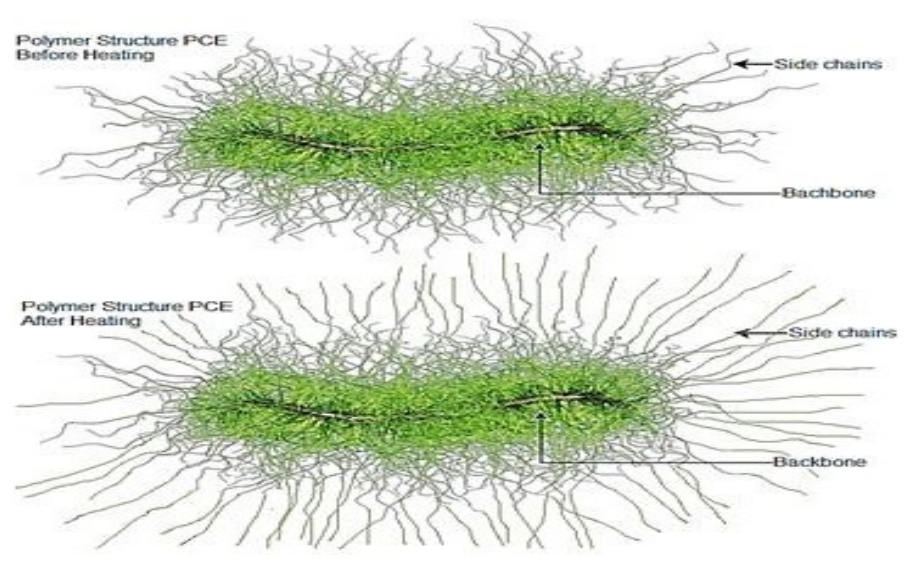

Fig. 9. Polymer structure PCE

\section{REFERENCES}

[1] S. Chandra and J. Bjornstrom, "Influence of super- plasticizer type and dosage on the slump loss of Portland cement mortars," Cement and Concrete Research, vol. 32, no. 10, pp. 1613-1619, 2002. DOI: $10.1016 / \mathrm{S} 0008-8846(02) 00838-4$

[2] A. Zingg, F. Winnefeld, L. Holzer, J. Pakusch, S. Becker, R. Figi and L. Gauckler, "Interaction of polycarboxylate-based superplasticizers with ce- ments containing different C3A amounts," Cement and Concrete Composites, vol. 31, no. 3, pp. 153-162, 2009. DOI: 10.1016/j.cemconcomp.2009.01.005

[3] K. Yamada, T. Takahashi, S. Hanehara and M. Mat- suhisa, "Effects of the chemical structure on the properties of polycarboxylate-type superplasticizer," Cement and Concrete Research, vol. $\quad 30$, no. 2, 197- 207, 2000. DOI: 10.1016/S0008-8846(99)00230-6

[4] W. F. Perenchio, D. A. Whiting and D. L. Kantro, "Water reduction, slump loss and entrained air void systems," Special Publication, vol. 62, no. 2, pp.

\section{7- 156, 1979.}

[5] N. P. Mailvagnum, "Slump loss in flowing concrete," Special Publication, vol. 62, no. 4, pp. 389-404, 1979.

[6] K. Yoshioka, E. Tazawa, K. Kawai and T. Enohata, "Adsorption characteristics of superplasticizers on cement component minerals," Cement and Concrete Research, vol. 32, no. 10, pp. 1507-1513, 2002.

DOI: $10.1016 / \mathrm{S} 0008-8846(02) 00782-2$

[7] P. K. Mehta, and P. J. M. Monteiro, Concrete: Mi- $\quad$ crostructure, Properties and Materials. New York, NY: McGraw-Hill Publishing, 2006. 
[8] K. Yamada, T. Takahashi, S. Hanehara and M. Mat- suhisa, "Effects of polyethlene oxide chains on the performance of polycarboxylate-type water-reducers," Cement and Concrete Research, vol. 35, no. 5, pp. 867-873, 2005.

DOI: $10.1016 /$ j.cemconres.2004.04.031

[9] T. C Holland, P. Gupta and V. M. Malhotra, "Ninth ACI international conference on superplasticizers and other chemical admixtures in concrete," 2009 [on- line]. Available: goo.gl/nYXeTK

[10] Q. Ran, P. Somasundaran, C. Miao, J. Liu, S. Wu and J. Shen, "Effect of the length of the side chains of comb-like copolymer dispersants on dispersion and rheological properties of concentrated ce- ment suspensions," Journal of Colloid and Inter- $\quad$ face Science, vol. 336, no. 2, pp. 624-633, 2009. DOI: $10.1016 /$ j.jcis.2009.04.057

[11] D. Hamada, T. Sato, F. Yomoto and T. Mizunuma, "Development of new superplasticizer and its ap- plication to self-compacting concrete," in 6th CAN- MET/ACI International Conference on Superplasti- cizters and Other Chemical Admixtures in Concrete, Nice, France, 2000.

[12] K. Yamada, S. Ogawa and S. Hanehara, "Control- ling of the adsorption and dispersing force of polycarboxylate-type superplasticizer by sulfate ion concentration in aqueous phase," Cement and Con- $\quad$ crete Research, vol. 31, no. 3, pp. 375-383, 2001.

[13] H. H. Bache, "Densified cement-based ultrafine particle-based material," in 2th International

Con- ference on Super-Pasticizer in Concrete, Ottawa, Canada, 1981.

[14] J. P. Baker, D. R. Stephens, H. W. Blanch and J. M. Prausnitz, "Swelling equilibria for acryloamide -based poliampholyte hydrogels," Macromolecules, vol. 25, no. 7, pp. 1955-1958, 1992.

DOI: $10.1021 / \mathrm{ma} 00033 \mathrm{a} 019$

[15] V. S. Ramachandran, R. F. Feldman and J. J. Beaudoin, Concrete Science, Treatise on Current Research, Lon- don. UK: Applied Science Publishers.

[16] G. Chiocchio and A. E. Paolini, "Optimum time for adding superplasticizer to Portland cement pastes," Cement and Concrete Research, vol. 15, no. 5, pp. 901-908, 1985.

DOI: $10.1016 / 0008-8846(85) 90157-7$
[17] A. Papo and L. Piani, "Effect of various superplas- ticizers on the rheological properties of Portland search, cement pastes," Cement and Concrete Revol. 34, no. 11, pp. 2097-2101, 2004.

DOI: $10.1007 / \mathrm{s} 11517-006-0063-\mathrm{z}$

[18] H. Uchikawa, D. Sawaki and S. Hanehara, "Inuence of kind and addition timing of organic admixture on the composition structure and property of fresh cement paste," Cement and Concrete Research, vol. 25, no. 2, pp. 353-364, 1995.

DOI: 10.1016/j.cemconres.2004.03.017

[19] K. Luke and A. Torres, "Influence of temperature and retarder on superplasticizer performance," Special Publication, vol. 302, pp. 93-112, 2015.

DOI: $10.1016 / 0008-8846(95) 00021-6$

[20] J. G. Cabrera, "The role of admixtures in high perfor- $\quad$ mance concrete," in International RILEM Conference Monterrey, Mexico, USA, 1999.

[21] V. M. Malhorta, "Superplasticizers and other chemi- cal admixtures in concrete," in Sixth CANMET/ACI International Conference, Nice, France, 2000.

[22] J. Golaszewski and J. Szwabowski, "Influence of superplasticizers on rheological behavior of fresh cement mortars," Cement and Concrete Re- $\quad$ search, vol. 34, no. 2, pp. 235-248, 2004.

DOI: $10.1016 /$ j.cemconres.2003.07.002

[23] P. F. G. Banfill, "The rheology of fresh mortar," Maga- $\quad$ zine of Concrete Research, vol. 43, no. 154, pp. 13-21, 1991. DOI: $10.1680 /$ macr.1991.43.154.13

[24] F. Winnefeld, S. Becker, J. Pakusch and T. Gotz, "Polymer structure/ concrete property relations of Hrwra," in 8th CANMET/ACI International Confer- ence on Recent Advances in Concrete Technology, Montreal, Canada, 2006.

[25] H. N. M. E. Mahmud, A. K. Obidul Huq and R. B. Yahya, $\quad$ "Polypyrrole conducting polymer: A novel adsor- bent for arsenic ions from aqueous solution," Interna- tional Journal of Technology and Engineering Studies, $\quad$ vol. 1, no. 4, pp. 129-135, 2015.

DOI: $10.20469 /$ ijtes.40004-4

[26] N. Maneechot, W. Supiwong and A. Tanomtong, "Chromosomal analysis and Nors polymorphism of bagarius suchus (Siluriformes: Sisoridae) by con- $\quad$ ventional banding and fish techniques," Journal of Applied and Physical Sciences, vol. 2, no. 1. pp. 10- 19, 2016. DOI: 10.20474/-japs2.1.2 